\title{
Thermodynamic equilibrium for the dehydration of 1-butanol to di-n-butyl ether
}

\author{
M. A. Pérez-Maciá, R. Bringué*, M. Iborra, J. Tejero, F. Cunill
}

Department of Chemical Engineering, University of Barcelona, C/Martí i Franquès, 1, 08028 Barcelona

*Corresponding author. Tel.:+34 93402 0155; Fax +34 934021291

E-mail addresses: pm.mariangeles@gmail.com (M. A. Pérez-Maciá), rogerbringue@ub.edu (R. Bringué),miborra@ub.edu (M. Iborra),jtejero@ub.edu (J. Tejero), fcunill@ub.edu (F. Cunill).

\begin{abstract}
The thermodynamic equilibrium of the bimolecular dehydration of 1-butanol to di-n-butyl ether (DNBE) and water in the liquid phase was studied. Equilibrium experiments were performed at $4 \mathrm{MPa}$ and in the temperature range of 413-463 K over the ion exchange resin Amberlyst-70. The thermodynamic equilibrium for the side reactions (dehydration to 1-butene, olefins isomerization, olefins hydration and branched ether formation) was also studied. The equilibrium constant for the dehydration reaction of 1-butanol to di-n-butyl ether and water was found to be independent of the operating temperature, within the limits of the experimental error $( \pm 5.2 \%)$. The experimental equilibrium constants at $413-463 \mathrm{~K}$ allows to estimate the standard enthalpy change of reaction $\left(\Delta_{\mathrm{r}} \mathrm{H}_{(\mathrm{l})}^{0}=-0.3 \pm 2.9 \mathrm{~kJ} \cdot \mathrm{mol}^{-1}\right)$ and the standard entropy change of reaction $\left(\Delta_{\mathrm{r}} \mathrm{S}^{0}{ }_{(1)}=26.8 \pm 6.7 \mathrm{~J} \cdot \mathrm{mol}^{-1} \cdot \mathrm{K}^{-1}\right)$. From these values the standard formation enthalpy $\left(\Delta_{\mathrm{f}} \mathrm{H}_{\text {DNBE,(l) }}^{0}\right)$ and the molar entropy of DNBE $\left(\mathrm{S}_{\mathrm{DNBE},(\mathrm{l})}^{0}\right)$ at $298.15 \mathrm{~K}$ were computed to be $370.5 \pm 10.9 \mathrm{~kJ} \cdot \mathrm{mol}^{-1}$ and $408.3 \pm 6.8 \mathrm{~J} \cdot \mathrm{mol}^{-1} \cdot \mathrm{K}^{-1}$ respectively.
\end{abstract}

Keywords: Di-n-butyl ether (DNBE); 1-butanol dehydration; Thermodynamic equilibrium; ionexchange resin

\section{Introduction}

During the last twenty years European Regulation has become increasingly stringent in terms of emissions standards (Regulation EC 715/2007), quality of fuels (Directive 2009/30/EC) and the mandatory use of biofuels, setting a $10 \%$ minimum target for the share of biofuels in transport petrol and diesel consumption by 2020 (Directive 2009/28/EC).

A valuable option to meet these requirements without modification of existing diesel engines is the reformulation of diesel to include oxygenates. A number of different oxygenates (various alcohols, ethers and esters) have been considered as diesel fuel components. Among them, linear monoethers show the best properties to be added to diesel given their high cetane number, cold flow properties and mixture stability (Pecci et al., 1991). Linear ethers have also proved to reduce diesel exhaust such as $\mathrm{CO}$, particulate matter and unburned hydrocarbons and to substantially improve the trade-off between particulate and $\mathrm{NO}_{\mathrm{x}}$ due to the presence of oxygen 
in the ether molecules (Marchionna et al., 1996). Di-n-butyl ether (DNBE) is considered a highly promising oxygenate as it keeps a good balance between cetane number and cold flow properties and, in addition, it can be obtained from biobutanol what means that it can be considered a new bioether.

In a previous work (Pérez et al., 2014) we showed that di-n-butyl ether can be successfully synthesized through the bimolecular dehydration of 1-butanol over acidic ion-exchange resins. Among the tested resins, Amberlyst-70 proved to be the most suitable catalyst for industrial use due to its high selectivity to DNBE and its thermal stability, up to $473 \mathrm{~K}$.

However, to develop a potential industrial process a reliable knowledge of the reaction kinetics and the chemical equilibrium is required and, to the best of our knowledge, equilibrium data for the liquid-phase DNBE synthesis have not been reported yet. To overcome this lack of thermodynamic data, in this work we present experimental values of the equilibrium constant of 1-butanol to di-n-butyl ether and water determined by direct measurement of the composition of the liquid mixture at equilibrium. The equilibrium constants of potential side reactions (intramolecular dehydration of 1-butanol to 1-butene, isomerization of 1-butene to cis-2-butene and trans-2-butene, olefins hydration to 2-butanol and 1-(1methylpropoxy) butane formation from the reaction between 1-butanol and the olefins) were also determined. From these values, thermodynamic properties such as the standard enthalpy change $\Delta_{\mathrm{r}} \mathrm{H}_{(1)}^{0}$, the standard entropy change $\Delta_{\mathrm{r}} \mathrm{S}_{(\mathrm{l})}^{0}$ and the standard Gibbs energy $\Delta_{\mathrm{r}} \mathrm{G}_{(1)}^{0}$ of reactions were computed and compared with estimated and experimental values found in data banks. Whenever possible, recommended values for these thermochemical properties, as well as for the standard enthalpy of formation $\left(\Delta_{\mathrm{f}} \mathrm{H}^{0}{ }_{(\mathrm{l})}\right)$ and for the standard molar entropy $\left(\mathrm{S}_{(\mathrm{l})}^{0}\right)$ for the compounds present in the system are provided.

\section{Materials and methods}

\subsection{Chemicals and catalyst}

1-butanol $(\geq 99.4 \%$ pure; $\leq 0.1 \%$ butyl ether; $\leq 0.1 \%$ water $)$ and DNBE $(\geq 99.0 \%$ pure $; \leq 0.05 \%$ water) supplied by Acros Organics, 1-butene ( $\geq 99.0 \%$ pure) and 1,4-dioxane ( $\geq 99.8 \%$ pure) supplied by Sigma Aldrich and cis-2-butene ( $\geq 98.0 \%$ pure) supplied by TCI were used without further purification. Deionised water (resistivity $18.2 \mathrm{~m} \Omega \cdot \mathrm{cm}$ ) was obtained in our laboratory. The macroreticular thermostable resin Amberlyst-70 supplied by Rohm and Haas was used as catalyst. Amberlyst-70 is a low cross-linked ( $8 \% \mathrm{DVB})$ chlorinated and sulfonated copolymer of styrene-divinybenzene. Its maximum operating temperature is $473 \mathrm{~K}$. The acid capacity, determined by titration against standard base following the procedure described by Fisher and Kunnin (1955), was found to be 2.65 meq. $\mathrm{H}^{+} / \mathrm{g}$. The catalyst was used in its commercial form (mean bead diameter $=0.59 \mathrm{~mm}$ ). 


\subsection{Experimental setup}

Experiments were carried out in a 100-mL-cylindrical high pressure autoclave (Autoclave Engineers, M010SS) made of 316 stainless steel (temperature limit: $232^{\circ} \mathrm{C}$, pressure range: 0 $15 \mathrm{MPa}$ ). The system was equipped with a magnetic drive stirrer and with a $400 \mathrm{~W}$ electrical furnace for heating. Temperature was measured by a thermocouple located inside the reactor and stirring speed was measured by a tachometer. Both operation variables were controlled to \pm $1^{\circ} \mathrm{C}$ and $\pm 1 \mathrm{rpm}$ respectively by an electronic control unit. The pressure was set to $4 \mathrm{MPa}$ by means of $\mathrm{N}_{2}$ to ensure that the medium is in liquid phase over the whole temperature range. One of the outlets of the reactor was connected directly to a liquid sampling valve, which injected $0.2 \mu \mathrm{L}$ of pressurized liquid into a gas-liquid chromatograph (Agilent Technologies, 7820A).

\subsection{Analysis}

The composition of the liquid mixture was analyzed in-line using a dimethylpolysiloxane HPPona $(50 \mathrm{~m}$ x $0.200 \mathrm{~mm} \times 0.50 \mu \mathrm{m})$ capillary column. Chromatograph parameters were as follows: helium ( $\geq 99.4 \%$ pure supplied by Abello Linde) at $70 \mathrm{~mL} \cdot \mathrm{min}^{-1}$ constant flow was used as the carrier gas; volume injection $0.2 \mu \mathrm{L}$; split ratio 100:1; inlet temperature $423 \mathrm{~K}$. The oven was programed with a $5.5 \mathrm{~min}$ initial hold at $423 \mathrm{~K}$, followed by a $50 \mathrm{~K} \cdot \mathrm{min}^{-1}$ ramp up to $453 \mathrm{~K}$ and held isotherm for $10 \mathrm{~min}$.

The chromatograph was equipped with a TCD detector and the used parameters were as follows: detector temperature $523 \mathrm{~K}$; reference flow $20 \mathrm{~mL} \cdot \mathrm{min}^{-1}$; makeup flow $4.9 \mathrm{~mL} \cdot \mathrm{min}^{-1}$.

\subsection{Procedure}

Preliminary experiments carried out at $423 \mathrm{~K}$ and $4 \mathrm{MPa}$ showed that, when starting from pure 1-butanol, equilibrium conversions are higher than $85 \%$. Because an important amount of di-nbutyl ether and water was expected in the reaction medium and given their immiscibility, 1,4dioxane was used as a solvent to avoid liquid phase separation. The selection of the solvent was made taking into account its stability under the working conditions (blank experiments showed that 1,4-dioxane does not undergo any chemical reaction); its lack of influence on the catalyst structure (Bringué et al., 2008); and because it was found in previous works that the use of this solvent does not alter the value of the chemical equilibrium constant (Delion et al., 1986). Wet resin (as provided by the supplier) was dried at $383 \mathrm{~K}$, firstly at $0.1 \mathrm{MPa}$ during $2 \mathrm{~h}$ and then at $1 \mathrm{kPa}$ overnight. The catalyst and $70 \mathrm{ml}$ of different mixtures of 1,4-dioxane, 1-butanol, DNBE, water, 1-butene, cis-2-butene and 2-butanol, with a composition presumably close to the equilibrium composition, were charged into the reactor. The mass of loaded catalyst ranged from 1 to $7 \mathrm{~g}$. In order to adjust the time needed to reach the equilibrium at the different working temperatures we used a higher amount of catalyst in experiments carried out at low temperature. After checking for leaks, the stirring speed was set at $500 \mathrm{rpm}$ and the mixture was 
heated up to the working temperature $(413-463 \mathrm{~K})$. When the temperature set point was reached the pressure was adjusted up to $4 \mathrm{MPa}$ by means of $\mathrm{N}_{2}$ in order to ensure liquid phase medium.

To follow the variation of the composition of the liquid mixture with time, liquid samples were taken out periodically and analyzed in-line as mentioned above. Experiments were considered finished when the calculated equilibrium constants had the same value along time, within the limits of experimental uncertainties.

\section{Results and discussion}

\subsection{Equilibrium constants}

Dehydration of 1-butanol over Amberlyst-70 gives place to di-n-butyl ether and water as the main products. Besides DNBE, some side products were detected in the reaction medium.

Figure 1 shows the proposed reaction scheme where 1-butene can be formed by intramolecular dehydration of 1-butanol [R2] or by DNBE decomposition [R3]. DNBE decomposition produces also 1-butanol. 1-butene isomerizes to cis-2-butene [R4] and trans-2-butene [R5]. Furthermore, cis-2-butene can isomerize to trans-2-butene [R6] and vice versa. The olefins can react with water to produce 2-butanol [R7-R9] or with 1-butanol to produce 1-(1methylpropoxy) butane [R10-R12]. More details about byproducts formation can be found elsewhere (Pérez et al., 2014).

\section{FIGURE 1}

It should be noted that from the group of reactions proposed only 6 reactions are stoichiometrically independent. One of the possible combination of stoichiometrically independent reactions is the group formed by the reactions marked with an asterisk $(*)$ in Figure 1. The rest of the reactions and the corresponding relation between equilibrium constants can be obtained as follows:

$$
\begin{array}{ll}
{\left[R_{3}\right]=\left[R_{2}\right]-\left[R_{1}\right]} & K_{e q, 3}=K_{e q, 2} / K_{e q, 1} \\
{\left[R_{4}\right]=\left[R_{5}\right]-\left[R_{6}\right]} & K_{e q, 4}=K_{e q, 5} / K_{e q, 6} \\
{\left[R_{8}\right]=\left[R_{7}\right]-\left[R_{5}\right]} & K_{e q, 8}=K_{e q, 7} / K_{e q, 5} \\
{\left[R_{9}\right]=\left[R_{7}\right]+\left[R_{6}\right]-\left[R_{5}\right]} & K_{e q, 9}=\left(K_{e q, 7} \cdot K_{e q, 6}\right) / K_{e q, 5} \\
{\left[R_{11}\right]=\left[R_{10}\right]-\left[R_{5}\right]} & K_{e q, 11}=K_{e q, 10} / K_{e q, 5} \\
{\left[R_{12}\right]=\left[R_{10}\right]+\left[R_{6}\right]-\left[R_{5}\right]} & K_{e q, 12}=\left(K_{e q, 10} \cdot K_{e q, 6}\right) / K_{e q, 5}
\end{array}
$$

The degree of ideality of the reaction medium is an important factor in a thermodynamic study and, because of the important dissimilarity between the compounds presents in the medium, the system is expected to deviate from ideality. To account for these deviations, the activity 
coefficients of all the species, $\gamma_{\mathrm{j}}$, were estimated by the UNIFAC-Dortmund predictive method (Weidlicht and Gmehling, 1987; Gmehling et al., 1993; Gmehling et al., 1998; Jakob et al., 2006). This method was selected because it presents the following advantages in front of the group contribution methods UNIFAC or ASOG: (1) better description of the temperature dependence; (2) better description of the real behavior in the dilute region; (3) it can be applied more reliably for systems involving molecules with very different size.

\section{FIGURE 2}

As an example of typical experiment, Figure 2 shows the evolution of the activities for all the species detected in the reaction medium at $423 \mathrm{~K}$. It must be pointed out that 1,4-dioxane has the higher activity $\left(\mathrm{a}_{\mathrm{dioxane}} \approx 0.69\right)$ because of its high concentration in the medium, followed by water $\left(\mathrm{a}_{\text {water }} \approx 0.32\right.$ ) whose high activity is due to its high activity coefficient (in all experiments higher than 2). Activities of 1-(1-methylpropoxy) butane, 2-butanol and 1-butene were in all cases very low due to their low concentration in the reaction medium.

In all experiments we observed a slightly decrease in the DNBE activity and a very slow increase in the 1-butene activity. This fact indicates that both intramolecular dehydration of 1butanol (R1) and DNBE decomposition (R3) could have not reached the chemical equilibrium at the end of the experiment. The increase in 1-butene activity gives place to a slight increase of 2-butenes (reactions R4 and R5), 2-butanol (reactions R7, R8 and R9) and 1-(1-methylpropoxy) butane (reactions R10, R11 and R12).

Because the reaction follows a parallel-series scheme, it was rather difficult to achieve a constant composition for all the species present in the medium. For this reason, it was considered that the system was in equilibrium when the computed values of $\mathrm{K}_{\mathrm{eq}, \mathrm{i}}$ were constant, within the limits of the experimental error. Thermodynamic equilibrium constants $\mathrm{K}_{\mathrm{eq}, \mathrm{i}}$ were computed from activities according to equation (7) where $\mathrm{K}_{\gamma, \mathrm{i}}$ and $\mathrm{K}_{\mathrm{x}, \mathrm{i}}$ are, respectively, the equilibrium constants of reaction $i$ in terms of activity coefficients and molar fractions of the species that take part in the reaction.

$$
K_{e q, i}=\prod_{j=1}^{S}\left(a_{j}\right)_{e}^{v_{j}}=\prod_{j=1}^{S}\left(\gamma_{j}\right)_{e}^{v_{j}}\left(x_{j}\right)_{e}^{v_{j}}=\prod_{j=1}^{S}\left(\gamma_{j}\right)_{e}^{v_{j}} \prod_{j=1}^{S}\left(x_{j}\right)_{e}^{v_{j}}=K_{\gamma, i} K_{x, i}
$$

Time evolution of the so-calculated equilibrium constants (see Figure 3) shows that, after $450 \mathrm{~h}$ of running, both 1-butanol intramolecular dehydration (R2, Figure $3 \mathrm{~b}$ ) and DNBE decomposition (R3, Figure $3 \mathrm{c}$ ), had not reached the chemical equilibrium, as mentioned above. However, the formation of 1-butene was rather slow, allowing a quick readjustment of the compositions for the rest of the reactions. This fact can be corroborated by observing that $\mathrm{K}_{\mathrm{eq}}$ were constant within the limits of the experimental error for the rest of the studied reactions. 
Thus, it was considered that these reactions were in pseudo-equilibrium state. It should be pointed out that, despite the very low amount of 2-butanol and 1-(1-methylpropoxy) butane detected in the reaction medium, the reactions involving these two compounds reached the chemical equilibrium quickly (see Figure 3 e and f) in contrast with the main reaction where the amount of DNBE was considerably higher but the corresponding reaction needed a longer time to reach the equilibrium (see Figure 3 a).

\section{FIGURE 3}

Table 1 gathers the values of $\mathrm{K}_{\gamma, \mathrm{i}}$ and $\mathrm{K}_{\mathrm{x}, \mathrm{i}}$ and the equilibrium constants $\mathrm{K}_{\text {eq,i }}$ for the group of stoichiometrically independent reactions marked with an asterisk $(*)$ in Figure 1. It can be observed that $\mathrm{K}_{\mathrm{x}, \mathrm{i}}$ decreases with temperature for all the reactions with exception of $\mathrm{R} 1$, where $\mathrm{K}_{\mathrm{x}, \mathrm{i}}$ remains constant within the limits of the experimental error.

In a similar way, $\mathbf{K}_{\gamma, \mathrm{i}}$ decreases with temperature for all the reactions. In reactions where water participates (R1, bimolecular dehydration of 1-butanol to di-n-butyl ether, and R7-R9, hydration of olefins to 2-butanol) the values of $\mathrm{K}_{\gamma, \mathrm{i}}$ are significantly different from unity showing the nonideality of the mixture. On the other hand, the values of $\mathrm{K}_{\gamma, \mathrm{i}}$ corresponding to olefins isomerization (R4-R6) are very close to unity. In these reactions only olefins are involved which have very similar activity coefficients.

Regarding $\mathrm{K}_{\mathrm{eq}, \mathrm{i}}$, the equilibrium constant for the bimolecular dehydration of 1-butanol to DNBE (R1) is high enough to state that the reaction is shifted to the ether formation at equilibrium. Furthermore, as it was mentioned before, the formation of 1-butene was extremely slow and the highest amount of 1-butene detected at the end of the experiments was rather low.

Consequently, the amount of the other byproducts was also very low. All this assures a good conversion level of 1-butanol to ether in industrial etherification processes. Moreover, $\mathrm{K}_{\mathrm{eq}, 1}$ hardly changes with temperature, pointing out that conversion is quite promising to produce the ether in all the experimental temperature range.

Data corresponding to the intramolecular dehydration of 1-butanol to 1-butene (R2), which is also part of the group of stoichiometrically independent reactions marked with an asterisk in Figure 1, is not included in Table 1 because the reaction did not reach the chemical equilibrium, as above mentioned. Despite that, it should be pointed out that the results suggest that the dehydration of 1-butanol to 1-butene is an endothermic reaction. This fact is in agreement with the general pattern found in literature about dehydration of alcohols to olefins (Bringué et al., 2008; Bringué et al., 2007; Casas et al., 2013).

For the rest of the reactions gathered in Table 1 it can be observed that $\mathrm{K}_{\mathrm{eq}, \mathrm{i}}$ decreases with temperature indicating that they are exothermic reactions. Olefins isomerization is shifted to 2- 
butenes formation and, among them, trans-2-butene is thermodynamically favored as it can be inferred from the $\mathrm{K}_{\mathrm{eq}, 6}$ values of R6 (isomerization cis - trans).

\section{TABLE 1}

Equation (7) is deduced considering that fugacity of liquids is a weak function of pressure and assuming that the fugacity of the liquid at the working temperature and pressure is equal to the fugacity of the liquid at the working temperature and at $0.1 \mathrm{MPa}$ of pressure. However, at high pressures this assumption can be inaccurate. In order to take into account the deviations in $\mathrm{K}_{\text {eq,i }}$ due to the difference between the working pressure (4 MPa) and the pressure at the standard state $(0.1 \mathrm{MPa})$, the Poynting correction factor $\mathrm{K}_{\Gamma}$ was evaluated as follows (Smith and Van Ness, 1987):

$$
K_{\Gamma}=\exp \left(\frac{P-1}{R T} \sum_{j=1}^{S} v_{j} V_{j}\right)
$$

where $\mathrm{P}$ is the working pressure and $v_{\mathrm{j}}$ and $\mathrm{V}_{\mathrm{j}}$ are respectively the stoichiometric coefficient and the molar volume of compound $j$.

At this point it is important to emphasize that previous simulations with the software Chemcad (http://www.chemstations.com/) were carried out in order to select the working pressure. These simulations showed that working at $4 \mathrm{MPa}$ ensures that, for the temperature range studied, the reaction medium is in liquid phase even when the amount of olefins, which are the most volatile compounds in the system, is high. Thus, the liquid phase was assured throughout the experiment. However, the working conditions are very close to the critical region of pure butenes, the critical points of butenes being (Tsonopoulos and Ambrose, 1996): $419.6 \mathrm{~K}$ and 4.02 MPa for 1-butene; 428.6 K and 3.99 MPa for trans-2-butene; and 435.6 K and 4.20 MPa for cis-2-butene. Accurate fluid properties in states near a pure component's vapor-liquid critical point are difficult to obtain both from experiments and from models (Poling at al., 2001). For this reason molar volumes $\mathrm{V}$ of butenes were not determined and consequently, the Poynting correction factor $\mathrm{K}_{\Gamma}$ was evaluated only for the main reaction, the bimolecular dehydration of 1-butanol to di-n-butyl ether.

The calculated Poynting correction factor $\mathrm{K}_{\Gamma}$ for the reaction of 1-butanol dehydration to ether at different temperatures (the molar volumes of 1-butanol, di-n-butyl ether and water was estimated by the Hankinson-Brobst-Thomson method (Poling at al., 2001)) ranged from 0.983 to 0.978 . Thus, the effect of $\mathrm{K}_{\Gamma}$ on the $\mathrm{K}_{\mathrm{eq}}\left(\mathrm{K}_{\mathrm{eq}}=\mathrm{K}_{\mathrm{x}} \cdot \mathrm{K}_{\gamma} \cdot \mathrm{K}_{\Gamma}\right)$ was lower than the experimental uncertainty. Therefore, it can be assumed that the effect of the working pressure on the equilibrium constant is negligible and the equilibrium constant is only a function of temperature. 


\subsection{Standard Gibbs free energy, enthalpy, and entropy of reaction}

Data corresponding to the standard Gibbs free energy $\left(\Delta_{\mathrm{r}} \mathrm{G}_{\mathrm{i},(1)}^{0}\right)$, enthalpy $\left(\Delta_{\mathrm{r}} \mathrm{H}_{\mathrm{i},(\mathrm{l})}^{0}\right)$ and entropy $\left(\Delta_{\mathrm{r}} \mathrm{S}_{\mathrm{i},(1)}^{0}\right)$ for the chemical reactions involved in the system under study are, in most cases, not reported previously in the open literature. A theoretical estimation of these thermochemical properties can be obtained as follows: (1) $\Delta_{\mathrm{r}} \mathrm{H}_{\mathrm{i},(1)}^{0}$ can be estimated from the standard heats of formation of the reactants and products involved reaction $i$; (2) $\Delta_{\mathrm{r}} \mathrm{S}_{\mathrm{i},(\mathrm{l})}^{0}$ can be estimated form the standard molar entropies of the reactants and products involved in reaction $i$ and; (3) $\Delta_{\mathrm{r}} \mathrm{G}_{\mathrm{i},(1)}^{0}$ can be estimated from equation (9):

$$
\Delta_{r} G_{i,(l)}^{0}=\Delta_{r} H_{i,(l)}^{0}-\Delta_{r} S_{i,(l)}^{0} \cdot T
$$

Table 2 gathers thermochemical data corresponding to the species involved in the reaction network at $298.15 \mathrm{~K}$. Most of these values were obtained from the open literature; however, to the best of our knowledge the following values are not available: the standard enthalpy of formation for 1-(1-methylpropoxy) butane and the liquid molar entropy of di-n-butyl ether and 1-(1-methylpropoxy) butane. The standard enthalpy of formation was estimated by the improved Benson's group-additivity method (Verevkin, 2002) and the molar entropies of the two ethers by the procedure described by Stull et al. (1969) (equations 10 to 13).

$S_{j,(l)}^{0}=S_{j,(g)}^{0}-\Delta_{v} S_{j}^{0}-\Delta_{c} S_{j}^{0}-\Delta_{i g} S_{j}^{0}$

where

$$
\begin{aligned}
& \Delta_{v} S_{j}^{0}=\Delta_{v a p} H_{j} / T \\
& \Delta_{c} S_{j}^{0}=-R \ln \left(P^{0} / P_{j}^{s}\right) \\
& \Delta_{i g} S_{j}^{0}=\frac{27}{32} \frac{R T_{c, j}^{3}}{P_{c, j} T^{3}} P^{0}
\end{aligned}
$$

Equation 10 involves, for compound $j$, the entropy change due to phase change $\left(\Delta_{\mathrm{v}} S_{j}^{0}\right)$, the effect of vapor compression from the saturation pressure $\mathrm{P}_{\mathrm{j}}^{\mathrm{s}}$ (vapor pressure at standard temperature) to the standard pressure $\mathrm{P}^{0}(1.013 \mathrm{bar})\left(\Delta_{\mathrm{c}} \mathrm{S}_{\mathrm{j}}^{0}\right)$ and the deviation of ideality of the vapor at $298.15 \mathrm{~K}$ and $1.013 \operatorname{bar}\left(\Delta_{\mathrm{ig}} \mathrm{S}_{\mathrm{j}}^{0}\right)$.

\section{TABLE 2}

The thermochemical data gathered in Table 2 allows estimating the theoretical standard enthalpy $\left(\Delta_{\mathrm{r}} \mathrm{H}_{\mathrm{i},(\mathrm{l})}^{0}\right)$, entropy $\left(\Delta_{\mathrm{r}} \mathrm{S}_{\mathrm{i},(\mathrm{l})}^{0}\right)$ and Gibbs free energy $\left(\Delta_{\mathrm{r}} \mathrm{G}_{\mathrm{i},(\mathrm{l})}^{0}\right)$ of the reactions at $298.15 \mathrm{~K}$ shown in Table 3. In order to corroborate these theoretically estimated values, the experimental standard enthalpy $\left(\Delta_{\mathrm{r}} \mathrm{H}_{\mathrm{i},(\mathrm{l})}^{0}\right)$, entropy $\left(\Delta_{\mathrm{r}} \mathrm{S}_{\mathrm{i},(\mathrm{l})}^{0}\right)$ and Gibbs free energy $\left(\Delta_{\mathrm{r}} \mathrm{G}_{\mathrm{i},(\mathrm{l})}^{0}\right)$ of the reactions were also estimated from the values of the equilibrium constants. As it is well known the thermodynamic equilibrium constant of the chemical reaction $i$ is related to the Gibbs free energy change $\left(\Delta_{\mathrm{r}} \mathrm{G}_{\mathrm{i}}^{0}\right)$ as follows: 


$$
\ln K_{e q, i}=\left(\frac{-\Delta_{r} G_{i}^{0}}{R T}\right)
$$

Substituting equation 9 in 14 the temperature dependence of the equilibrium constant can be expressed by

$\ln K_{e q, i}=\frac{-\Delta_{r} H_{i}^{0}}{R T}+\frac{\Delta_{r} S_{i}^{0}}{R}$

Thus, assuming that the enthalpy change of reaction does not vary over the temperature range, it is possible to obtain the experimental values of $\Delta_{\mathrm{r}} \mathrm{H}_{\mathrm{i},(1)}^{0}$ and $\Delta_{\mathrm{r}} \mathrm{S}_{\mathrm{i},(\mathrm{l})}^{0}$ by fitting equation 15 to the experimental (obtained from composition at equilibrium) values of $\mathrm{K}_{\mathrm{eq}, \mathrm{i}}$.

The resulting fitted linear models obtained by least squares regression are shown in Table 3. Figure 4 shows the experimental values of $\ln \mathrm{K}_{\mathrm{eq}}$ versus $1 / \mathrm{T}$ for the reactions in pseudoequilibrium state (dots), the values predicted by the corresponding fitted linear models (solid line) and the confidence intervals at the $95 \%$ confidence level for the values predicted by these models (dotted lines). For each model an F-test was performed to evaluate its accuracy from a statistical standpoint. In all cases the F-test proved that the linear models represented adequately reactions equilibrium data.

\section{FIGURE 4}

Table 3 shows the values of $\Delta_{\mathrm{r}} \mathrm{H}_{\mathrm{i},(\mathrm{l})}^{0}$ and $\Delta_{\mathrm{r}} \mathrm{S}_{\mathrm{i},(\mathrm{l})}^{0}$ obtained from equation 15, and $\Delta_{\mathrm{r}} \mathrm{G}_{\mathrm{i},(\mathrm{l})}^{0}$ computed from equation 9 for each reaction. $\Delta_{\mathrm{r}} \mathrm{H}_{\mathrm{i},(\mathrm{l})}^{0}$ and $\Delta_{\mathrm{r}} \mathrm{S}_{\mathrm{i},(\mathrm{l})}^{0}$ are, as a matter of fact, average values in the temperature range 413-443 $\mathrm{K}$, and it is assumed that they hardly change with temperature so that such values are representative that the ones at $298.15 \mathrm{~K} . \Delta_{\mathrm{r}} \mathrm{G}_{\mathrm{i},(1)}^{0}$ was estimated at $298.15 \mathrm{~K}$ by means of Eq. 9. Experimental values reported in the literature (Literature data) as well as theoretical values (Theoret.) of $\Delta_{\mathrm{r}} \mathrm{H}_{\mathrm{i},(\mathrm{l})}^{0}$ (estimated from the standard heats of formation, Table 2), $\Delta_{\mathrm{r}} \mathrm{S}_{\mathrm{i},(\mathrm{l})}^{0}$ (estimated form the standard molar entropies, Table 2) and $\Delta_{\mathrm{r}} \mathrm{G}_{\mathrm{i},(1)}^{0}$ (estimated from equation 9) are also included in Table 3.

\section{TABLE 3}

Next, the conclusions deduced by comparing the experimental values of $\Delta_{\mathrm{r}} \mathrm{H}_{\mathrm{i},(1)}^{0}, \Delta_{\mathrm{r}} \mathrm{S}_{\mathrm{i},(\mathrm{l})}^{0}$ and $\Delta_{\mathrm{r}} \mathrm{G}_{\mathrm{i},(\mathrm{l})}^{0}$ with theoretical values (and with literature data when available) are discussed.

Bimolecular dehydration of 1-butanol to DNBE. The theoretical $\Delta_{\mathrm{r}} \mathrm{H}_{1,(1)}^{0}=-7.8 \pm 9.8 \mathrm{~kJ} \cdot \mathrm{mol}^{-1}$ estimated from the standard heats of formation presents a low absolute value suggesting that the exothermicity of the bimolecular dehydration of 1-butanol to di-n-butyl ether and water is very low, being almost an athermic reaction. This fact agree with the experimentally determined $\Delta_{\mathrm{r}} \mathrm{H}_{1,(1)}^{0}=-0.3 \pm 2.9 \mathrm{~kJ} \cdot \mathrm{mol}^{-1}$ and is also in agreement with the constancy of $\mathrm{K}_{\text {eq, } 1}$ with temperature (see Table 1). Furthermore, the experimental $\Delta_{\mathrm{r}} \mathrm{H}_{1,(1)}^{0}$ found in this work is in the 
trend shown by values of other linear symmetrical dialkyl ether found in the literature (Bringué et al., 2008; Bringué et al., 2007; Casas et al., 2013) (Table 4). From the experimental $\Delta_{\mathrm{r}} \mathrm{H}_{1,(1)}^{0}$ in Table 3 and $\Delta_{\mathrm{f}} \mathrm{H}_{\mathrm{j},(1)}^{0}$ of 1-butanol and water in Table 2 a value of $\Delta_{\mathrm{f}} \mathrm{H}_{\mathrm{DNBE},(1)}^{0}=-370.5 \pm 10.9$ $\mathrm{kJ} \cdot \mathrm{mol}^{-1}$ at $298.15 \mathrm{~K}$ for DNBE can be obtained. This value agrees with that obtained by Colomina et al. (1965) from combustion enthalpies, enforcing the reliability of the experimental equilibrium data obtained for the main reaction.

The experimental $\Delta_{\mathrm{r}} \mathrm{S}_{1,(1)}^{0}$ found in this work $\left(26.8 \pm 6.7 \mathrm{~J} \cdot \mathrm{mol}^{-1} \cdot \mathrm{K}^{-1}\right)$ is lower than the theoretical value $\left(39.5 \mathrm{~J} \cdot \mathrm{mol}^{-1} \cdot \mathrm{K}^{-1}\right)$. As mentioned above, the theoretical $\Delta_{\mathrm{r}} \mathrm{S}_{1,(\mathrm{l})}^{0}$ was obtained using the value of $\mathrm{S}_{\mathrm{DNBE},(\mathrm{g})}^{0}$ estimated by an improved Benson group-additive method (Verevkin, 2002) and equations 10 to 13 (Stull et al., 1969). To the best of our knowledge, no experimental value of $\mathrm{S}_{(1)}^{0}$ for DNBE has been published yet. From the experimental $\Delta_{\mathrm{r}} \mathrm{S}^{0}{ }_{1,(1)}$ in Table 3 and $\mathrm{S}_{\mathrm{j},(1)}^{0}$ of 1-butanol and water in Table 2 a value of $\mathrm{S}_{\mathrm{DNBE},(1)}^{0}=408.3 \pm 6.8 \mathrm{~J} \cdot \mathrm{mol}^{-1} \cdot \mathrm{K}^{-1}$ at $298.15 \mathrm{~K}$ for DNBE can be obtained. This value is slightly lower (3\%) than that predicted by the modified Benson method $\left(421.04 \mathrm{~J} \cdot \mathrm{mol}^{-1} \cdot \mathrm{K}^{-1}\right)$.

Table 4 shows the $\Delta_{\mathrm{r}} \mathrm{H}_{\mathrm{i},(1)}^{0}, \Delta_{\mathrm{r}} \mathrm{S}_{\mathrm{i},(1)}^{0}$ and $\Delta_{\mathrm{r}} \mathrm{G}_{\mathrm{i},(1)}^{0}$ for the intermolecular dehydration of 1-butanol (present work), 1-pentanol (Bringué et al., 2007), 1-hexanol (Bringué et al., 2008), and 1octanol (Casas et al., 2013). A clear trend can be observed for the three thermochemical properties. Both $\Delta_{\mathrm{r}} \mathrm{H}_{\mathrm{i},(\mathrm{l})}^{0}$ and $\Delta_{\mathrm{r}} \mathrm{G}_{\mathrm{i},(\mathrm{l})}^{0}$ becomes less negative (exothermic) as the length of the ether decreases. On the other hand, $\Delta_{\mathrm{r}} \mathrm{S}_{\mathrm{i},(1)}^{0}$ increases as the length of the ether decreases. It should be pointed out that, for the four reactions, the theoretical value of $\Delta_{\mathrm{r}} \mathrm{H}_{\mathrm{i},(\mathrm{I})}^{0}$ overestimates the one experimentally found.

\section{TABLE 4}

Olefins isomerization (R4-R6). The experimental values of $\Delta_{\mathrm{r}} \mathrm{H}_{\mathrm{i},(1)}^{0}$ corresponding to olefins isomerizations are in agreement with both, those found in the literature and the estimated theoretical values.

Regarding $\Delta_{\mathrm{r}} \mathrm{S}_{\mathrm{i},(\mathrm{l})}^{0}$, the experimental value corresponding to the isomerization of 1-butene to cis2-butene (R4) is also in agreement with the theoretical one. However, the experimental $\Delta_{\mathrm{r}} \mathrm{S}_{\mathrm{i},(\mathrm{l})}^{0}$ of both the isomerization of 1-butene to trans-2-butene (R5) and the isomerization of cis-2butene to trans-2-butene (R6) are lower than the theoretical values. Some discrepancies about the standard entropy at $298.15 \mathrm{~K}$ of the trans-2-butene isomer $\left(\mathrm{S}_{\text {trans-(1) }}^{0}\right)$ can be found in the literature (Guttman and Pitzer, 1945; Takeda et al., 1991). From the equilibrium data of this work it is possible to compute $S_{\text {trans-(1) }}^{0}$ by two ways: (1) from the experimental values of $\Delta_{\mathrm{r}} S_{5,(1)}^{0}$ and $\mathrm{S}^{0}{ }_{1-\text { butene,(l) }}$ shown in Table 2 a value of $\mathrm{S}_{\text {trans-(1) }}^{0}=214.3 \pm 5.3 \mathrm{~J} \cdot \mathrm{mol}^{-1} \cdot \mathrm{K}^{-1}$ is obtained; (2) from the experimental values of $\Delta_{\mathrm{r}} \mathrm{S}_{6,(1)}^{0}$ and $\mathrm{S}_{\text {cis-(1) }}^{0}$ shown in Table 3 a value of $\mathrm{S}_{\text {trans-(1) }}^{0}=217.4$ $\pm 0.4 \mathrm{~J} \cdot \mathrm{mol}^{-1} \cdot \mathrm{K}^{-1}$ is obtained. From these two values a mean $\mathrm{S}_{\text {trans-(1) }}^{0}=215.8 \pm 2.9 \mathrm{~J} \cdot \mathrm{mol}^{-1} \cdot \mathrm{K}^{-1}$ 
was computed . This value is slightly higher than that reported by Guttman and Pitzer (1945) $\left(205.39 \mathrm{~J} \cdot \mathrm{mol}^{-1} \cdot \mathrm{K}^{-1}\right)$ and slightly lower than that estimated by the improved Benson groupadditive method $\left(221.78 \mathrm{~J} \cdot \mathrm{mol}^{-1} \cdot \mathrm{K}^{-1}\right)$.

Olefins hydration to 2-butanol (R7-R9). Experimental values of $\Delta_{\mathrm{r}} \mathrm{H}_{\mathrm{i},(\mathrm{l})}^{0}, \Delta_{\mathrm{r}} \mathrm{S}_{\mathrm{i},(\mathrm{l})}^{0}$ and $\Delta_{\mathrm{r}} \mathrm{G}_{\mathrm{i},(\mathrm{l})}^{0}$ for the hydrations of olefins to 2-butanol differ significantly from the theoretical values. Following the same reasoning as described with previous reactions the mean values $\Delta_{\mathrm{f}} \mathrm{H}^{0}{ }_{2-}$ butanol,(1) $=-359.9 \pm 4.1 \mathrm{~kJ} \cdot \mathrm{mol}^{-1}$ and $\mathrm{S}_{2 \text {-butanol,(l) }}^{0}=185.9 \pm 7.2 \mathrm{~J} \cdot \mathrm{mol}^{-1} \cdot \mathrm{K}^{-1}$ for 2-butanol were obtained at $298 \mathrm{~K}$ which are, respectively, $5 \%$ and $13 \%$ lower than the data found in the literature. These differences can be ascribed to uncertainty in chemical analysis (olefins and 2butanol were minor components at equilibrium).

1-(1-methylpropoxy) butane formation (R10-R12). Like in olefins hydration, experimental values of $\Delta_{\mathrm{r}} \mathrm{H}_{\mathrm{i},(1)}^{0}, \Delta_{\mathrm{r}} \mathrm{S}_{\mathrm{i},(1)}^{0}$ and $\Delta_{\mathrm{r}} \mathrm{G}_{\mathrm{i},(1)}^{0}$ for the 1-(1-methylpropoxy) butane formation differ significantly from the theoretical values. Following the same procedure, the mean value

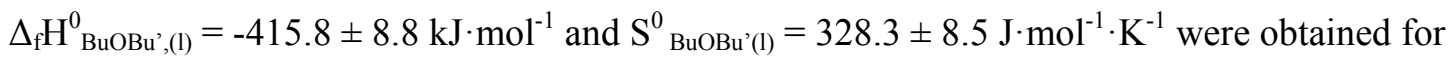
1-(1-methylpropoxy) butane at $298.15 \mathrm{~K}$. These values are, respectively, $6.4 \%$ and $22.7 \%$ lower than the values estimated by an improved Benson group-additive method. The important differences observed can be attributed to both the uncertainty in chemical analysis (olefins and 1-(1-methylpropoxy) butane were minor components) and a poor estimate of 1-(1methylpropoxy) butane formation enthalpy and molar entropy by the improved Benson groupadditive method.

\section{Conclusions}

The equilibrium constant for the bimolecular dehydration of 1-butanol to di-n-butyl ether and water was experimentally determined. Its value was found to be high enough to state that the reaction is shifted to the ether formation at equilibrium. Furthermore, the formation of 1-butene was extremely slow and, consequently, the rest of secondary products were also found in very low concentrations. As a consequence, a good conversion level of 1-butanol to the linear ether could be expected in industrial etherification processes.

The equilibrium constant for the dehydration reaction of 1-butanol to di-n-butyl ether and water was found to be independent of the operating temperature within the limits of the experimental error. That explains the very low value of the enthalpy change of reaction found (practically zero), which is in the trend showed by the reaction enthalpy change of other lineal symmetrical di-alkyl ethers found in the literature. From equilibrium data a value of $\Delta_{\mathrm{f}} \mathrm{H}_{(1)}^{0}=-370.5 \pm 10.9$ $\mathrm{kJ} \cdot \mathrm{mol}^{-1}$ for DNBE was obtained at $298.15 \mathrm{~K}$ which agrees with that one found in literature data bank within the limits of the experimental error.

Some differences between the values of $\Delta_{\mathrm{r}} \mathrm{S}^{0}{ }_{(1)}$ for the dehydration of 1-butanol to di-n-butyl ether computed from equilibrium data and estimated from standard molar entropies were 
observed. Based on this fact, the value $\mathrm{S}_{(1)}^{0}=408.3 \pm 6.8 \mathrm{~J} \cdot \mathrm{mol}^{-1} \cdot \mathrm{K}^{-1}$ for DNBE is proposed. This value is slightly lower than that predicted by the modified Benson method (421.04 J $\cdot \mathrm{mol}^{-}$ $\left.{ }^{1} \cdot \mathrm{K}^{-1}\right)$.

Isomerizations between olefins proved to be exothermic with an $\Delta_{\mathrm{r}} \mathrm{H}^{0}{ }_{(1)}$ of $-9.7 \pm 2.0 \mathrm{~J} \cdot \mathrm{mol}^{-1} \cdot \mathrm{K}^{-1}$ for the isomerization of 1-butene to cis-2-butene, $-13.0 \pm 2.4 \mathrm{~J} \cdot \mathrm{mol}^{-1} \cdot \mathrm{K}^{-1}$ for the isomerization of 1-butene to trans-2-butene and $-3.2 \pm 0.2 \mathrm{~J} \cdot \mathrm{mol}^{-1} \cdot \mathrm{K}^{-1}$ for the isomerization of cis-2-butene to trans-2-butene. These values are in agreement with those estimated from the standard formation enthalpies. Some disagreements regarding the value of the standard molar entropy of trans-2butene can be found in the literature. From equilibrium data, the value $\mathrm{S}_{(1)}^{0}=215.8 \pm 2.9 \mathrm{~J} \cdot \mathrm{mol}^{-}$ ${ }^{1} \cdot \mathrm{K}^{-1}$ for trans-2-butene is proposed.

Side reactions of olefins hydration and branched ether synthesis were proved to be also exothermic.

\section{Acknowledgment}

Financial support was provided by the Science and Education Ministry of Spain (project: CTQ2010-16047).

\section{Nomenclature}

$\mathrm{a}_{\mathrm{j}}$ activity of compound $j$

DNBE di-n-butyl ether

DVB di-vinyl benzene

$\Delta_{\mathrm{c}} \mathrm{S}_{\mathrm{j}}^{0} \quad$ effect of vapor compression from the saturation pressure $\mathrm{P}_{\mathrm{j}}^{\mathrm{s}}$ to the standard pressure $\mathrm{P}^{0}$ for compound $j\left(\mathrm{~J} \cdot \mathrm{mol}^{-1} \cdot \mathrm{K}^{-1}\right)$

$\Delta_{\mathrm{f}} \mathrm{H}_{\mathrm{j},(\mathrm{l})}^{0} \quad$ liquid-phase standard molar enthalpy change of formation of compound $j$ $\left(\mathrm{kJ} \cdot \mathrm{mol}^{-1}\right)$

$\Delta_{\mathrm{ig}} \mathrm{S}_{\mathrm{j}}^{0} \quad$ deviation of ideality of the vapor at $298.15 \mathrm{~K}$ and 1.013 bar for compound $j$ $\left(\mathrm{J} \cdot \mathrm{mol}^{-1} \cdot \mathrm{K}^{-1}\right)$

$\Delta_{\mathrm{r}} \mathrm{G}_{\mathrm{i},(\mathrm{l})}^{0} \quad$ liquid-phase standard free energy change of reaction $i\left(\mathrm{~kJ} \cdot \mathrm{mol}^{-1}\right)$

$\Delta_{\mathrm{r}} \mathrm{H}^{0}{ }_{\mathrm{i},(\mathrm{l})} \quad$ liquid-phase standard molar enthalpy change of reaction $i\left(\mathrm{~kJ} \cdot \mathrm{mol}^{-1}\right)$

$\Delta_{\mathrm{r}} \mathrm{S}_{\mathrm{i},(\mathrm{l})}^{0} \quad$ liquid-phase standard molar entropy change of reaction $i\left(\mathrm{~J} \cdot \mathrm{mol}^{-1} \cdot \mathrm{K}^{-1}\right)$

$\Delta_{\text {vap }} \mathrm{H}_{\mathrm{j}}^{0} \quad$ standard vaporization enthalpy of compound $\mathrm{j}\left(\mathrm{J} \cdot \mathrm{mol}^{-1}\right)$

$\Delta_{\mathrm{v}} \mathrm{S}_{\mathrm{j}}^{0} \quad$ entropy change due to phase change for compound $j\left(\mathrm{~J} \cdot \mathrm{mol}^{-1} \cdot \mathrm{K}^{-1}\right)$

$\mathrm{K}_{\mathrm{eq}, \mathrm{i}} \quad$ thermodynamic equilibrium constant of reaction $i$

$\mathrm{K}_{\gamma, \mathrm{i}} \quad$ equilibrium constant of reaction $i$ in terms of activity coefficients

$\mathrm{K}_{\Gamma} \quad$ Poynting correction factor

$\mathrm{K}_{\mathrm{x}, \mathrm{i}} \quad$ equilibrium constant of reaction $i$ in terms of molar fractions

$\mathrm{P} \quad$ pressure $(\mathrm{Pa})$ 


$\begin{array}{ll}\mathrm{P}^{0} & \text { standard pressure (Pa) } \\ \mathrm{P}_{\mathrm{c}, \mathrm{j}} & \text { critical pressure of compound } j \\ \mathrm{P}_{\mathrm{j}}^{\mathrm{s}} & \text { vapor pressure at standard temperature for compound } \mathrm{j}(\mathrm{Pa}) \\ \mathrm{R} & \text { gas constant }\left(\mathrm{J} \cdot \mathrm{mol}^{-1} \cdot \mathrm{K}^{-1}\right) \\ \mathrm{V}_{\mathrm{j}} & \text { molar volume of compound } j\left(\mathrm{~m}^{3} \cdot \mathrm{mol}^{-1}\right) \\ \mathrm{S}_{\mathrm{j},(\mathrm{g})}^{0} & \text { gas-phase molar entropy of compound } j\left(\mathrm{~J} \cdot \mathrm{mol}^{-1} \cdot \mathrm{K}^{-1}\right) \\ \mathrm{S}_{\mathrm{j},(\mathrm{l})}^{0} & \text { liquid-phase molar entropy of compound } j\left(\mathrm{~J} \cdot \mathrm{mol}^{-1} \cdot \mathrm{K}^{-1}\right) \\ \mathrm{T} & \text { temperature }(\mathrm{K}) \\ \mathrm{TCD} & \text { thermal conductivity detector } \\ \mathrm{T}_{\mathrm{c}, \mathrm{j}} & \text { critical temperature of compound } \mathrm{j} \\ \mathrm{x}_{\mathrm{j}} & \text { molar fraction of compound } j\end{array}$

\section{Subscript}

BuOBu' 1-(1-methylpropoxy) butane

\section{Greek leters}

$\gamma_{j} \quad$ activity coefficients of compound $j$

$v_{\mathrm{j}} \quad$ stoichiometric coefficient of compound $j$

\section{References}

Andon, R.J.L.; Connett, J.E.; Counsell, J.F.; Lees, E.B.; Martin, J.F., 1971. Thermodynamic properties of organic oxygen compounds: xxvii racemate of - butan-2-ol and (+)-butan-2-ol. J. Chem. Soc. A, 661-664.

Bringué, R.; Tejero, J.; Iborra, M.; Izquierdo, J.F.; Fite, C.; Cunill, F., 2007. Experimental study of the chemical equilibria in the liquid-phase dehydration of 1-pentanol to di-n-pentyl ether, Ind. Eng. Chem. Res. 46, 6865-6872.

Bringué, R.; Tejero, J.; Iborra, M.; Fité, C.; Izquierdo, J. F.; Cunill, F., 2008. Study of the chemical equilibrium of the liquid-phase dehydration of 1-hexanol to di-hexyl ether. J. Chem. Eng. Data 53, 2854-2860.

Casas, C.; Fité, C.; Iborra, M.; Tejero, J.; Cunill, F., 2013. Chemical equilibrium of the liquidphase dehydration of 1-octanol to 1-(Octyloxy)octane, J. Chem. Eng. Data 58, 741-748.

Chao, J.; Rossini, F.D., 1965. Heats of combustion, formation, and isomerization of nineteen alkanols, J. Chem. Eng. Data 10, 374-379.

Chase, M.W., Jr., 1998. NIST-JANAF Thermochemical tables, Fourth Edition, J. Phys. Chem. Ref. Data, Monograph 9, 1998, 1-1951.

Colomina, M.; Pell, A.S.; Skinner, H.A.; Coleman, D.J., 1965. Heats of combustion of four dialkylethers, Trans. Faraday Soc. 61, 2641. 
Counsell, J.F.; Hales, J.L.; Martin, J.F., 1965. Thermodynamic properties of organic oxygen compounds. Part 16. Butyl alcohol, Trans. Faraday Soc. 61, 1869-1875.

Delion, A.; Torck, B.; Hellin, M., 1986. Equilibrium constant for the liquid-phase hydration of isobutylene over ion-exchange resin. Ind. Eng. Chem. Process Des. Dev. 25, 889-893.

Fisher S.; Kunnin, R., 1955. Routine exchange capacity determinations of ion exchange resins. Anal. Chem. 27, 1191-1194.

Gmehling, J.; Li, J.; Schiller M., 1993. A Modified UNIFAC Model. 2. Present parameter matrix and results for different thermodynamic properties. Ind. Eng. Chem. Res. 32, 178-193.

Gmehling, J.; Lohmann, J.; Jakob, A.; Li, J.; Joh, R., 1998. A Modified UNIFAC (Dortmund) Model. 3. Revision and extension. Ind. Eng. Chem. Res. 37, 4876-4882.

Guttman, L.; Pitzer, K.S., 1945. trans-2-Butene. The heat capacity, heats of fusion and vaporization, and vapor pressure. The entropy and barrier to internal rotation, J. Am. Chem. Soc. $67,324-327$.

http://www.chemstations.com/ (03/2012)

http://webbook.nist.gov/chemistry/ (15/07/2014)

Jakob, A.; Grensemann, H.; Lohmann, J.; Gmehling, J., 2006. Further development of modified UNIFAC (Dortmund): revision and extension 5. Ind. Eng. Chem. Res. 45, 7924-7933.

Majer, V.; Svoboda, V., 1985. Enthalpies of vaporization of organic compounds: A critical review and data compilation, Blackwell Scientific Publications, Oxford.

Marchionna, M.; Patrini, R.; Giavazzi, F.; Pecci, G.C., 1996. Symposium on removal of aromatics, sulfur and alkenes from gasoline and diesel, 212th National Meeting, ACS, 585.

Meyer, E.F.; Stroz, D.G., 1972. Thermodynamics of n-butene isomerization, J. Am. Chem. Soc. 94, 6344-6347.

Pecci, G.C.; Clerici, M. G.; Giavazzi, M. G.; Ancillotti, F.; Marchionna, M.; Patrini, R., 1991. Oxygenated diesel fuels. Part 1: Structures and properties correlation. Proceedings of the ninth international symposium on alcohol fuels Vol. 1; Florence, Italy; p 321.

Pérez, M.A.; Bringué, R.; Iborra, M.; Tejero, J.; Cunill, F., 2014. Ion exchange resins as catalysts for the liquid-phase dehydration of 1-butanol to di-n-butyl ether. Appl. Catal., A: General. 482, 38-48.

Poling, B. E.; Prausnitz, J. M.; O’Connell, J. P., 2001. The properties of gases and liquids, 5th ed.; McGraw-Hill Companies, chapter 4.

Prosen, E.J.; Maron, F.W.; Rossini, F.D., 1951. Heats of combustion, formation, and insomerization of ten C4 hydrocarbons, J. Res. NBS, 46, 106-112.

Smith, J. M.; Van Ness, H. C., 1987. Introduction to chemical engineering thermodynamics, 4th ed.; McGraw-Hill: Singapore; chapter 15. 
Stull, D. R.; Westrum, E. F., Jr.; Sinke, G. C., 1969. The chemical thermodynamics of organic compounds; John Wiley: New York.

Takeda, K.; Yamamuro, O.; Suga, H., 1991. Thermodynamic study of 1-butene. Exothermic and endothermic enthalpy relaxations near the glass transition, J. Phys. Chem. Solids 22, 607-615.

Tsonopoulos, C.; Ambrose, D., 1996. Vapor-liquid critical properties of elements and compounds. 6. Unsaturated aliphatic hydrocarbons, J. Chem. Eng. Data 41, 645-656.

Verevkin S. P., 2002. Improved Benson increments for the estimation of standard enthalpies of formation and enthalpies of vaporization of alkyl ethers, acetals, ketals, and ortho esters, J. Chem. Eng. Data 47, 1071-1097.

Weidlicht, U.; Gmehling, J., 1987. A Modified UNIFAC Model. 1. Prediction of VLE, hE, and gamma infinite. Ind. Eng. Chem. Res. 26, 7, 1372-1381. 


\section{Caption of Figures}

Figure 1. Reaction scheme. Reactions stoichiometrically independent are marked with an asterisk $(*)$.

Figure 2. Evolution of activities over time (1g of catalyst, $\mathrm{T}=423 \mathrm{~K}, \mathrm{P}=4 \mathrm{MPa}, 500 \mathrm{rpm}$ ). (•)

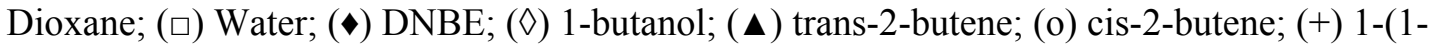
methylpropoxy) butane; (ロ) 2-butanol; ( $\Delta$ ) 1-butene.

Figure 3. Evolution of the equilibrium constants with time for the experiment shown in Figure 2

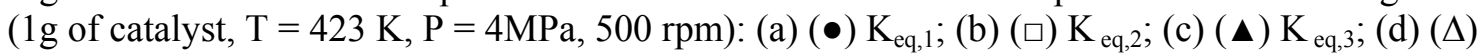

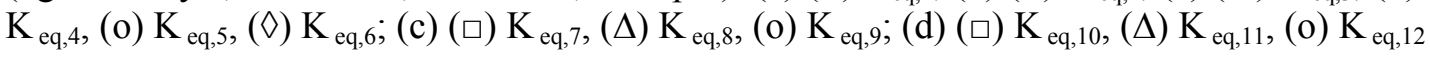

Figure 4. $\ln \mathrm{K}_{\mathrm{eq}, \mathrm{i}}$ versus 1/T. Dots refer to mean experimental values; solid lines refer to values predicted with equation 15; and dotted lines refer to the intervals at $95 \%$ confidence level for predicted values. 


[R2]*

FIGURE 1 


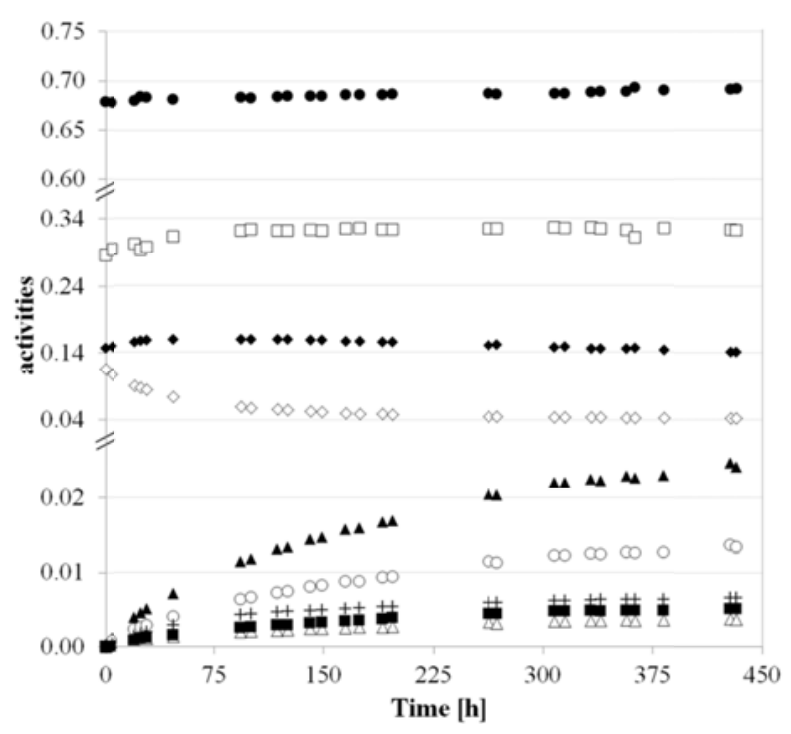

FIGURE 2 

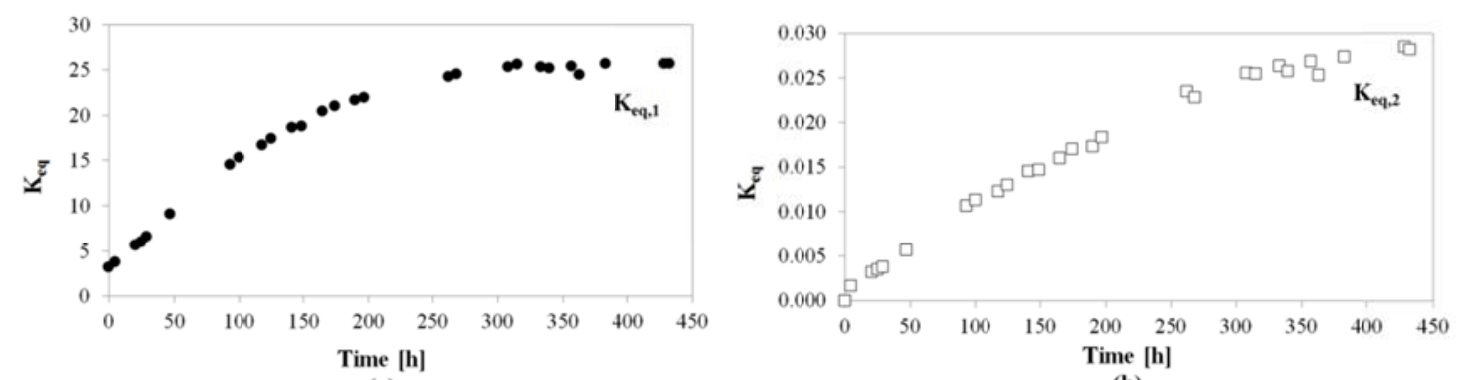

(a)
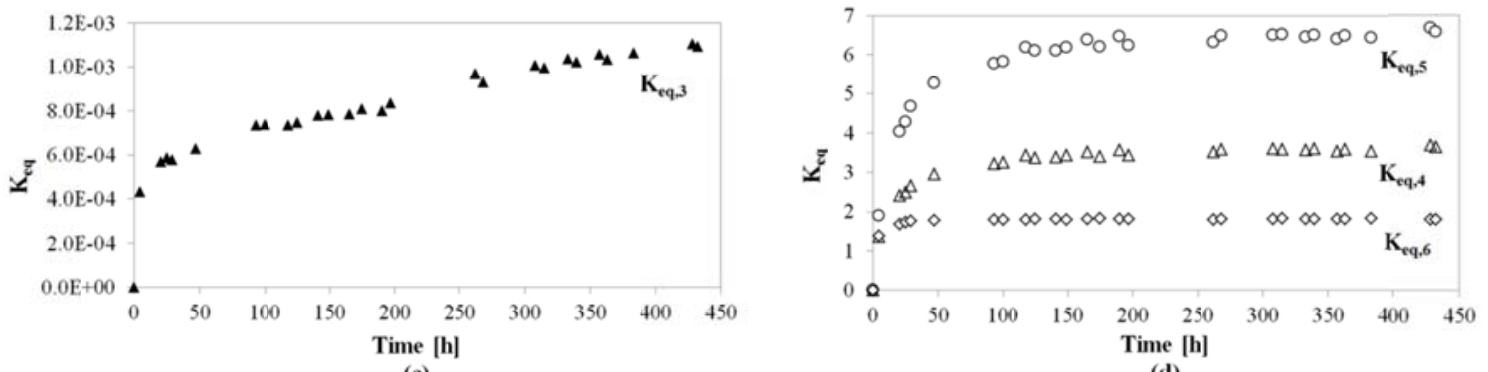

(c)

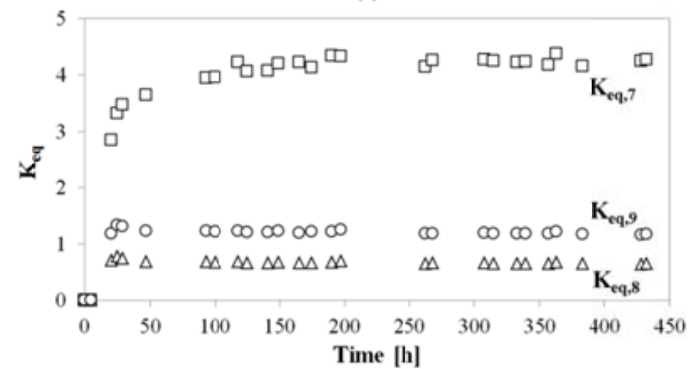

(e)

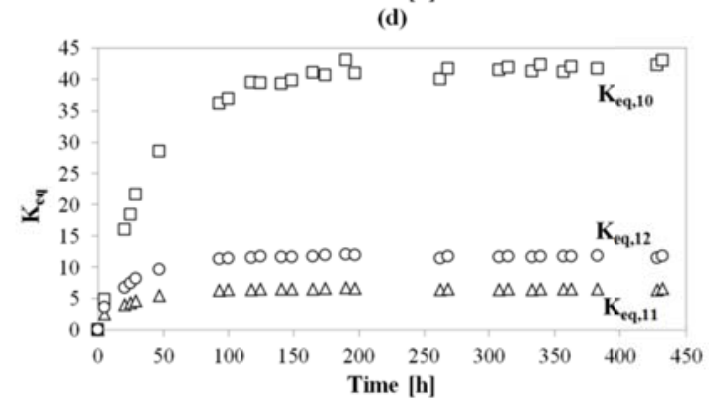

FIGURE 3 


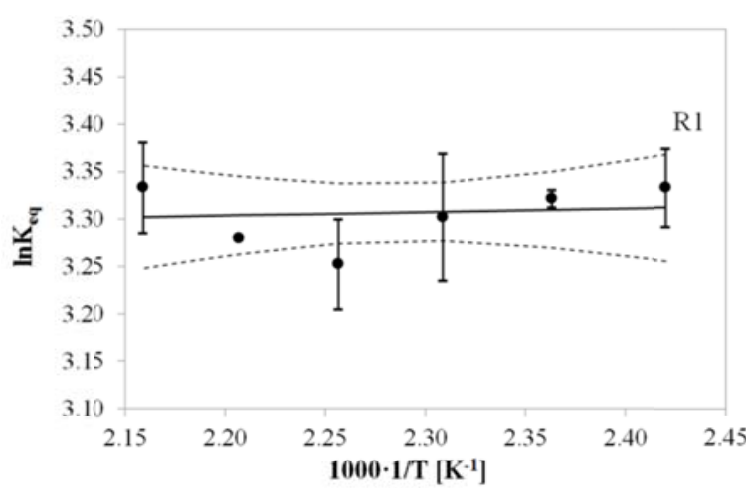

(a)

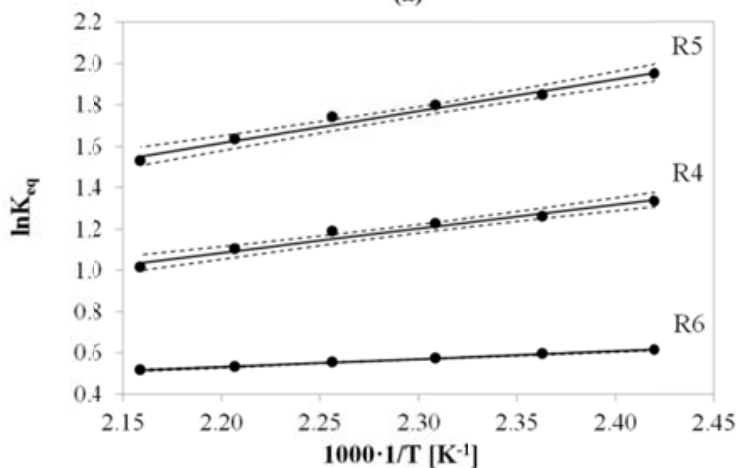

(b)

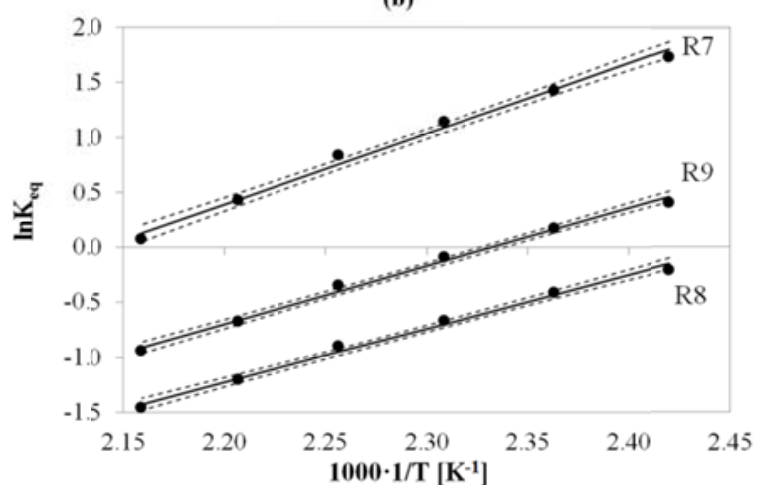

(c)

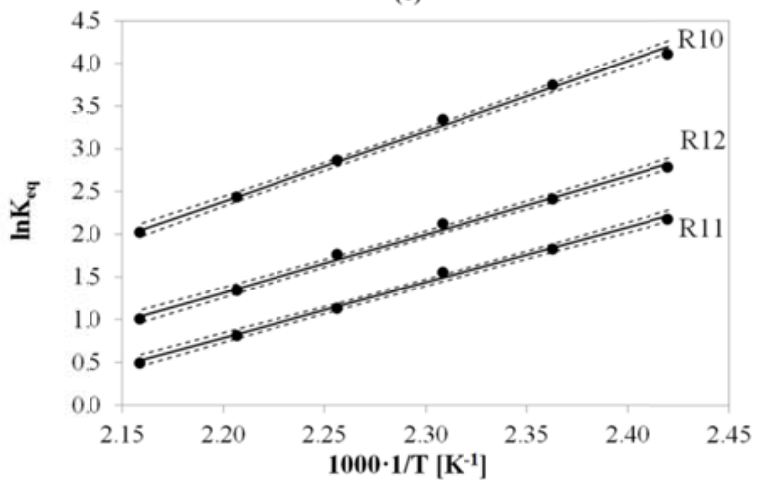

(d)

FIGURE 4 
Table 1. Mean values and standard uncertainties of the equilibrium constants determined in the temperature range of 413-463 K and $4 \mathrm{MPa}$. (R1) bimolecular dehydration of 1-butanol to di-nbutyl ether, (R5) isomerization of 1-butene to trans-2-butene, (R6) isomerization of cis-2-butene to trans-2-butene, (R7) hydration of 1-butene to 2-butanol and (R10) reaction between 1-butene and 1-butanol to yield 1-(1-methyl propoxy) butane.

\begin{tabular}{|c|c|c|c|c|}
\hline & $\mathbf{T}[\mathbf{K}]$ & $\mathbf{K}_{\mathbf{x}}$ & $\mathbf{K}_{\mathrm{Y}}$ & $K_{\text {eq }}$ \\
\hline \multirow[t]{6}{*}{ R1 } & 413 & $12.8 \pm 0.7$ & $2.19 \pm 0.01$ & $28.0 \pm 1.1$ \\
\hline & 423 & $12.7 \pm 0.2$ & $2.18 \pm 0.01$ & $27.7 \pm 0.2$ \\
\hline & 433 & $13.0 \pm 0.7$ & $2.09 \pm 0.03$ & $27.2 \pm 1.8$ \\
\hline & 443 & $12.7 \pm 0.3$ & $2.03 \pm 0.05$ & $25.9 \pm 1.2$ \\
\hline & 453 & 13.7 & 1.94 & 26.6 \\
\hline & 463 & $14.6 \pm 0.6$ & $1.92 \pm 0.03$ & $28.1 \pm 1.3$ \\
\hline \multirow[t]{6}{*}{ R5 } & 413 & $6.6 \pm 0.1$ & $1.06224 \pm 0.00003$ & $7.0 \pm 0.1$ \\
\hline & 423 & $6.0 \pm 0.4$ & $1.058 \pm 0.003$ & $6.4 \pm 0.4$ \\
\hline & 433 & $5.8 \pm 0.3$ & $1.052 \pm 0.005$ & $6.0 \pm 0.3$ \\
\hline & 443 & $5.48 \pm 0.02$ & $1.04 \pm 0.01$ & $5.70 \pm 0.03$ \\
\hline & 453 & 5.1 & 1.01 & 5.1 \\
\hline & 463 & $4.65 \pm 0.07$ & $0.99 \pm 0.01$ & $4.62 \pm 0.07$ \\
\hline \multirow[t]{6}{*}{ R6 } & 413 & $1.848 \pm 0.002$ & 1 & $1.848 \pm 0.002$ \\
\hline & 423 & $1.813 \pm 0.002$ & 1 & $1.813 \pm 0.002$ \\
\hline & 433 & $1.775 \pm 0.003$ & 1 & $1.775 \pm 0.003$ \\
\hline & 443 & $1.742 \pm 0.002$ & 1 & $1.742 \pm 0.002$ \\
\hline & 453 & 1.702 & 1 & 1.702 \\
\hline & 463 & $1.6747 \pm 0.0002$ & 1 & $1.6747 \pm 0.0002$ \\
\hline \multirow[t]{6}{*}{ R7 } & 413 & $15.9 \pm 0.3$ & $0.3565 \pm 0.0003$ & $5.7 \pm 0.1$ \\
\hline & 423 & $11.7 \pm 1.0$ & $0.357 \pm 0.008$ & $4.2 \pm 0.3$ \\
\hline & 433 & $8.9 \pm 0.6$ & $0.35 \pm 0.01$ & $3.1 \pm 0.1$ \\
\hline & 443 & $7.15 \pm 0.04$ & $0.32 \pm 0.03$ & $2.3 \pm 0.2$ \\
\hline & 453 & 5.4 & 0.28 & 1.5 \\
\hline & 463 & $4.0 \pm 0.1$ & $0.27 \pm 0.01$ & $1.08 \pm 0.06$ \\
\hline \multirow[t]{6}{*}{$\mathrm{R} 10$} & 413 & $63.7 \pm 0.5$ & $0.95 \pm 0.01$ & $60.4 \pm 0.1$ \\
\hline & 423 & $46.4 \pm 2.0$ & $0.91 \pm 0.03$ & $42.3 \pm 0.4$ \\
\hline & 433 & $30.9 \pm 3.2$ & $0.91 \pm 0.03$ & $28.2 \pm 2.2$ \\
\hline & 443 & 23.4 & 0.74 & 17.4 \\
\hline & 453 & 16.5 & 0.69 & 11.3 \\
\hline & 463 & $11.5 \pm 0.4$ & $0.65 \pm 0.03$ & $7.5 \pm 0.2$ \\
\hline
\end{tabular}


Table 2. Thermochemical data of species involved in the reaction network at $298.15 \mathrm{~K}$. Standard formation enthalpy $\left(\Delta_{\mathrm{f}} \mathrm{H}_{(\mathrm{l})}^{0}\right)$, standard vaporization enthalpy $\left(\Delta_{\text {vap }} \mathrm{H}^{0}\right)$ and standard molar entropy $\left(\mathrm{S}_{(1)}^{0}\right)$.

\begin{tabular}{|c|c|c|c|c|c|}
\hline & $\begin{array}{c}\Delta_{\mathrm{f}} \mathbf{H}_{(\mathrm{g})}^{0} \\
\mathrm{~kJ} \cdot \mathrm{mol}^{-1}\end{array}$ & $\begin{array}{c}\Delta_{\text {vap }} \mathbf{H}^{0} \\
\mathbf{k J} \cdot \mathbf{m o l}^{-1}\end{array}$ & $\begin{array}{c}\Delta_{\mathrm{f}} \mathbf{H}_{(\mathrm{l})}^{0} \\
\mathbf{k J} \cdot \mathbf{m o l}^{-1}\end{array}$ & $\begin{array}{c}\mathbf{S}_{(\mathrm{g})}^{0} \\
\mathbf{J} \cdot \mathrm{mol}^{-1} \cdot \mathbf{K}^{-1}\end{array}$ & $\begin{array}{c}\mathbf{S}_{(\mathrm{I})}^{0} \\
\mathbf{J} \cdot \mathbf{m o l}^{-1} \cdot \mathbf{K}^{-1}\end{array}$ \\
\hline 1-butanol & & & $-328 \pm 4^{d}$ & & $225.73^{i}$ \\
\hline DNBE & & $45^{\mathrm{b}}$ & $-378 \pm 1^{e}$ & $506.65^{\mathrm{c}}$ & $421.04^{\mathrm{j}}$ \\
\hline Water & & & $-285.83^{f}$ & & $69.95 \pm 0.03^{\mathrm{f}}$ \\
\hline 1-butene & $-0.63 \pm 0.79^{\mathrm{a}}$ & $20.88^{\mathrm{b}}$ & $-21.51 \pm 0.79^{g}$ & & $229.06^{\mathrm{k}}$ \\
\hline trans-2-butene & $-10.8 \pm 1^{\mathrm{a}}$ & $21.97^{\mathrm{b}}$ & $-32.77 \pm 1^{\mathrm{g}}$ & & $163.5^{\mathrm{k}}$ \\
\hline cis-2-butene & $-7.7 \pm 1.3^{\mathrm{a}}$ & $22.7^{\mathrm{b}}$ & $-30.4 \pm 1.3^{g}$ & & $220^{k}$ \\
\hline 2-butanol & & & $-342.7 \pm 0.59^{h}$ & & $213.1^{1}$ \\
\hline 1-(1-methylpropoxy) butane & & $43.61 \pm 0.85^{\mathrm{c}}$ & $-390.7^{c}$ & $509.84^{\mathrm{c}}$ & $424.61^{j}$ \\
\hline
\end{tabular}

${ }^{\mathrm{a}}$ Prosen et al. (1951).

${ }^{\mathrm{b}}$ Majer and Svoboda (1985).

${ }^{c}$ Estimated by a modified Benson method (Verevkin, 2002).

${ }^{\mathrm{d}}$ NIST average of values.

${ }^{\mathrm{e}}$ Colomina et al. (1965).

${ }^{\mathrm{f}}$ Chase (1998).

${ }^{g}$ Estimated according to the common definition $\Delta_{\mathrm{f}} \mathrm{H}^{0}{ }_{(\mathrm{l})}=\Delta_{\mathrm{f}} \mathrm{H}^{0}{ }_{(\mathrm{g})}-\Delta_{\text {vap }} \mathrm{H}^{0}$.

${ }^{\mathrm{h}}$ Chao and Rossini (1965).

${ }^{\mathrm{i}}$ Counsell et al. (1965).

${ }^{\mathrm{j}}$ Calculated by the equation proposed by Stull et al. (1969).

${ }^{\mathrm{k}}$ Takeda et al. (1991).

${ }^{1}$ Andon et al. (1971). 
Table 3. Standard enthalpy $\left(\Delta_{\mathrm{r}} \mathrm{H}_{\mathrm{i},(\mathrm{l})}^{0}\right)$, entropy $\left(\Delta_{\mathrm{r}} \mathrm{S}_{\mathrm{i},(\mathrm{l})}^{0}\right)$ and Gibbs energy $\left(\Delta_{\mathrm{r}} \mathrm{G}_{\mathrm{i},(\mathrm{l})}^{0}\right)$ for the reactions of the system at $298.15 \mathrm{~K}$

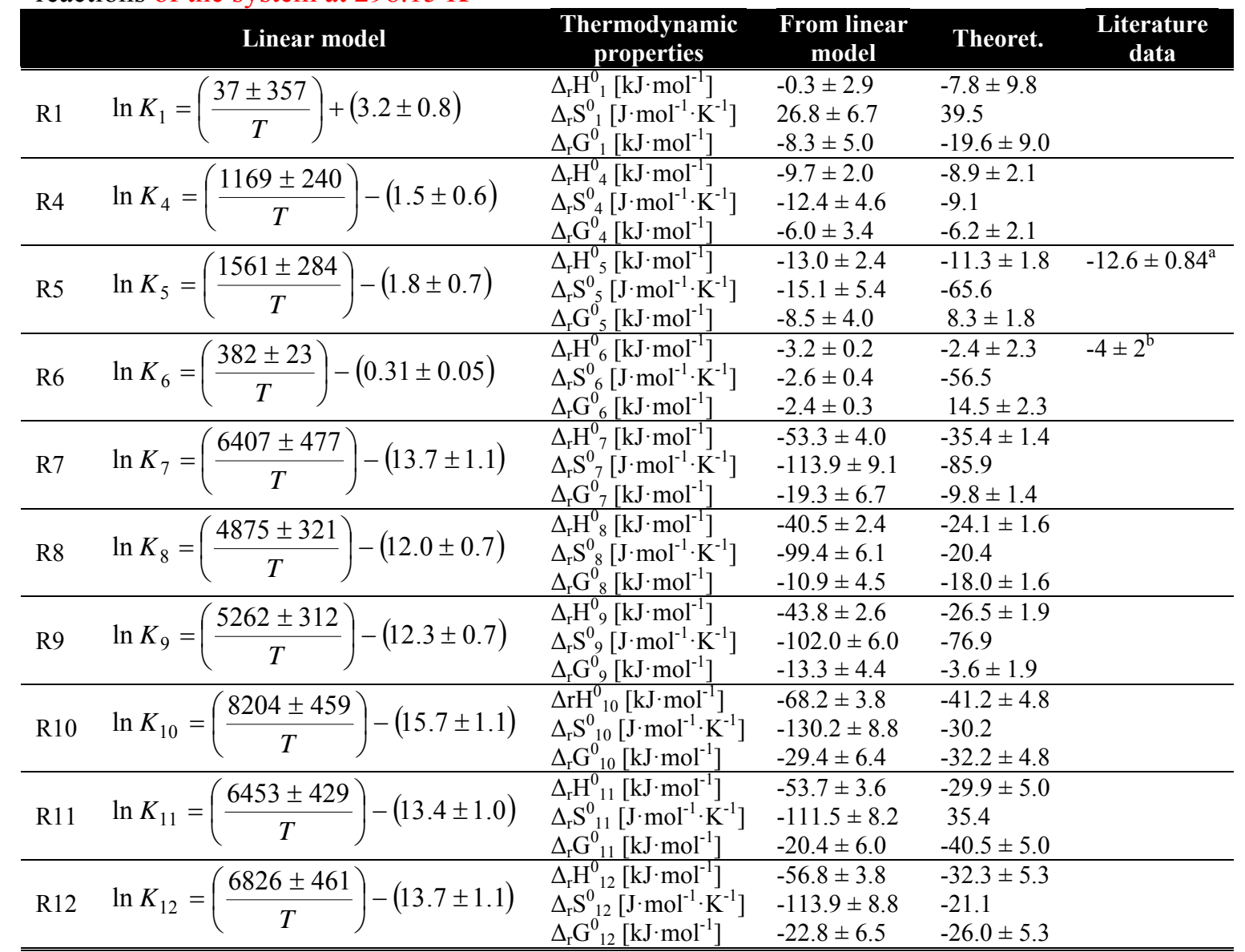

${ }^{\mathrm{a}}$ Meyer and Stroz (1972).

${ }^{b}$ NIST average of values (http://webbook.nist.gov/chemistry/). 
Table 4. Standard enthalpy $\left(\Delta_{\mathrm{r}} \mathrm{H}_{\mathrm{i},(1)}^{0}\right)$, entropy $\left(\Delta_{\mathrm{r}} \mathrm{S}_{\mathrm{i},(\mathrm{l})}^{0}\right)$ and Gibbs energy $\left(\Delta_{\mathrm{r}} \mathrm{G}_{\mathrm{i},(\mathrm{l})}^{0}\right)$ changes for the synthesis reaction of di-n-butyl ether (DNBE), di-n-pentyl ether (DNPE), di-n-hexyl ether (DNHE) and di-n-octyl ether (DNOE) in the liquid phase at 298,15 K assuming $\Delta_{\mathrm{r}} \mathrm{H}_{\mathrm{i},(1)}^{0}$ constant over the temperature range $423-463 \mathrm{~K}$.

\begin{tabular}{lcccccc} 
& \multicolumn{2}{c}{$\begin{array}{c}\Delta_{\mathrm{I}} \mathrm{H}_{(1)}^{0} \\
\mathrm{~kJ} \mathrm{~mol}^{-1}\end{array}$} & \multicolumn{2}{c}{$\begin{array}{c}\Delta_{\mathrm{r}} \mathrm{S}^{-} \\
\mathrm{J} \mathrm{mol}^{-1}\end{array}$} & \multicolumn{2}{c}{$\begin{array}{c}\Delta_{\mathrm{T}} \mathrm{G}_{(1)}^{0} \\
\mathrm{~kJ} \mathrm{~mol}^{-1}\end{array}$} \\
& Experimental & Theoretical & Experimental & Theoretical & Experimental & Theoretical \\
\hline DNBE & $-0.3 \pm 2.9$ & $-7.8 \pm 9.8$ & $26.8 \pm 6.7$ & 39.5 & $-8.3 \pm 5.0$ & $-19.6 \pm 9.0$ \\
DNPE & $-6.5 \pm 0.6$ & -17.8 & $18.1 \pm 1.4$ & -48.4 & $-11.9 \pm 1.1$ & -3.4 \\
DNHE & $-8.5 \pm 0.2$ & -11.9 & $15.2 \pm 0.5$ & 13 & $-13.0 \pm 0.4$ & -15.8 \\
DNOE & $-13.5 \pm 1.7$ & -15.9 & $14.0 \pm 4.0$ & -15.5 & $-17.7 \pm 2.1$ & -11.3 \\
\hline
\end{tabular}

